\title{
Arresting an Unusual Amide Tautomer Using Divalent Cations
}

Somnath M. Kashid ${ }^{\dagger *}$, Reman K. Singh ${ }^{\S}$, Hyejin Kwon\#, Yung Sam Kim*\#, Arnab Mukherjee*§, and Sayan Bagchi*广†

$\dagger$ Physical and Materials Chemistry Division, CSIR-National Chemical Laboratory, Pune 411008, India † Academy of Scientific and Innovative Research (AcSIR), Ghaziabad- 201002, India

$\S$ Department of Chemistry, Indian Institute of Science Education and Research, Pune 411008, India. \# Department of Chemistry, Ulsan National Institute of Science and Technology (UNIST), 50 UNISTgil, Ulsan 44919, Korea 


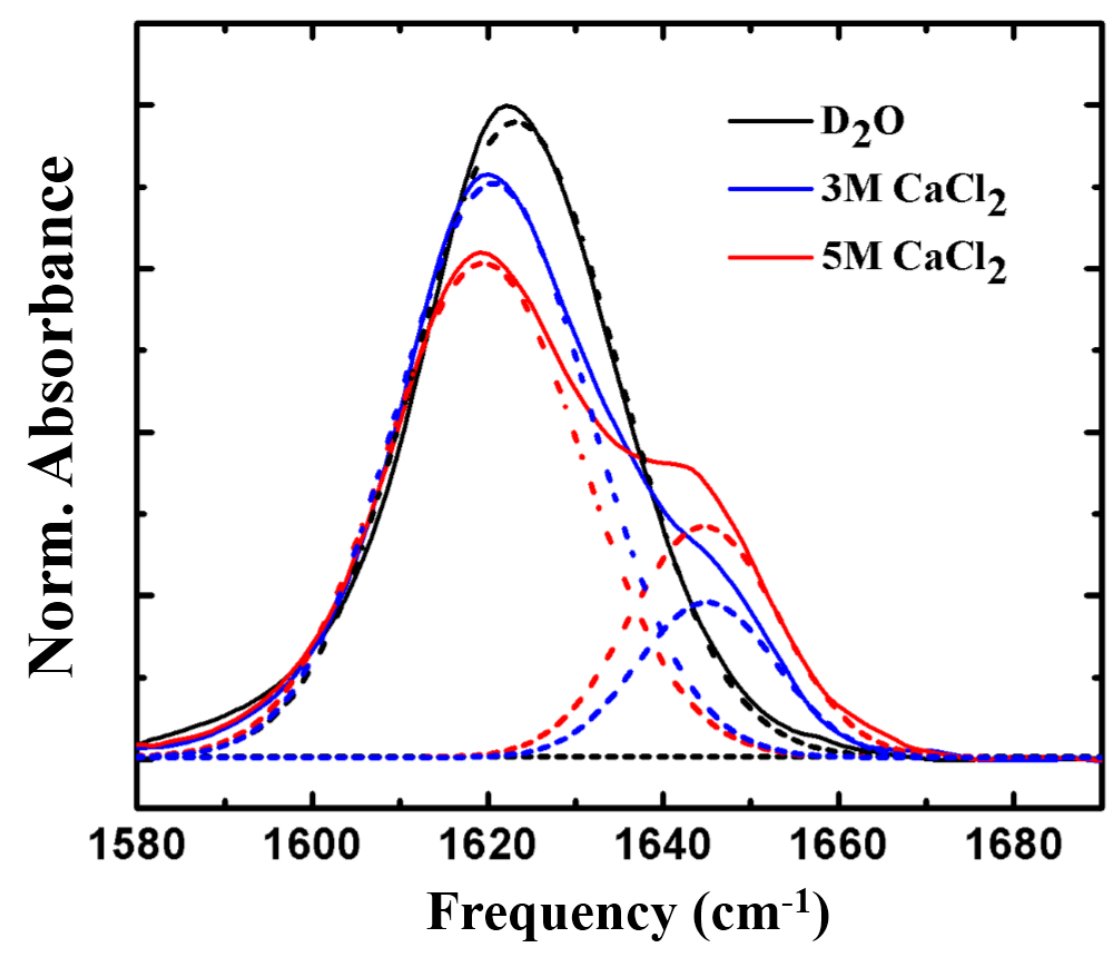

Figure S1. IR spectra (solid curves) of N-methylacetamide (NMA) in aqueous solution containing $\mathrm{CaCl}_{2}$ of three different concentrations. The spectra in presence of $\mathrm{Ca}^{2+}$ are fitted to two Gaussian profiles (dotted curves). The spectrum in neat water $\left(\mathrm{D}_{2} \mathrm{O}\right)$ is also shown as reference. All the spectra have been normalized to the area under the curve.

Table S1. Peak frequencies obtained from Gaussian fits.

\begin{tabular}{|c|c|c|}
\hline \multirow{2}{*}{ Solvent } & \multicolumn{2}{|c|}{ Frequency $\left(\mathrm{cm}^{-1}\right)$} \\
\cline { 2 - 3 } & Lower frequency & Higher frequency \\
\hline $\mathrm{D}_{2} \mathrm{O}$ & 1623.22 & 1644.95 \\
\hline $3 \mathrm{M} \mathrm{CaCl}_{2}$ & 1620.64 & 1644.68 \\
\hline $5 \mathrm{M} \mathrm{CaCl}_{2}$ & 1619.51 & \multicolumn{1}{|c|}{} \\
\hline
\end{tabular}




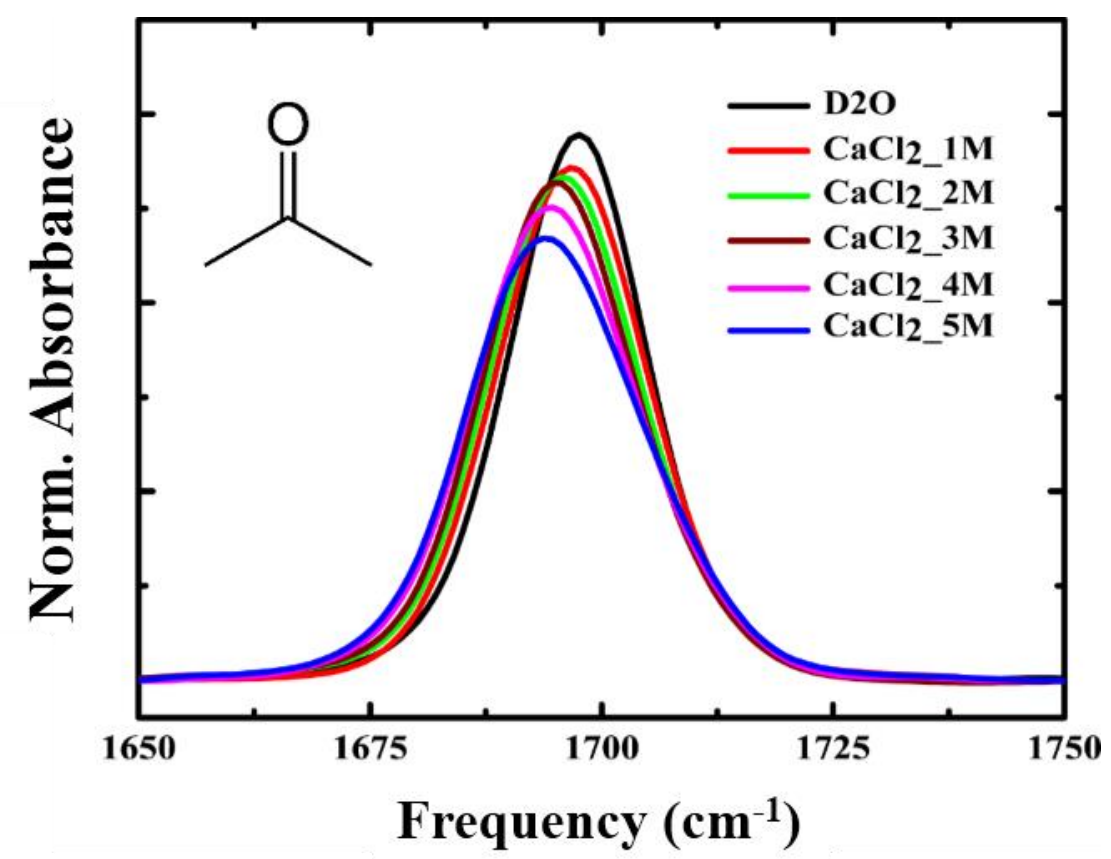

Figure S2. IR spectrum of acetone in aqueous solution containing $\mathrm{CaCl}_{2}$ of five different concentrations. The spectrum in neat water $\left(\mathrm{D}_{2} \mathrm{O}\right)$ is also shown as reference. All the spectra have been normalized to the area under the curve.

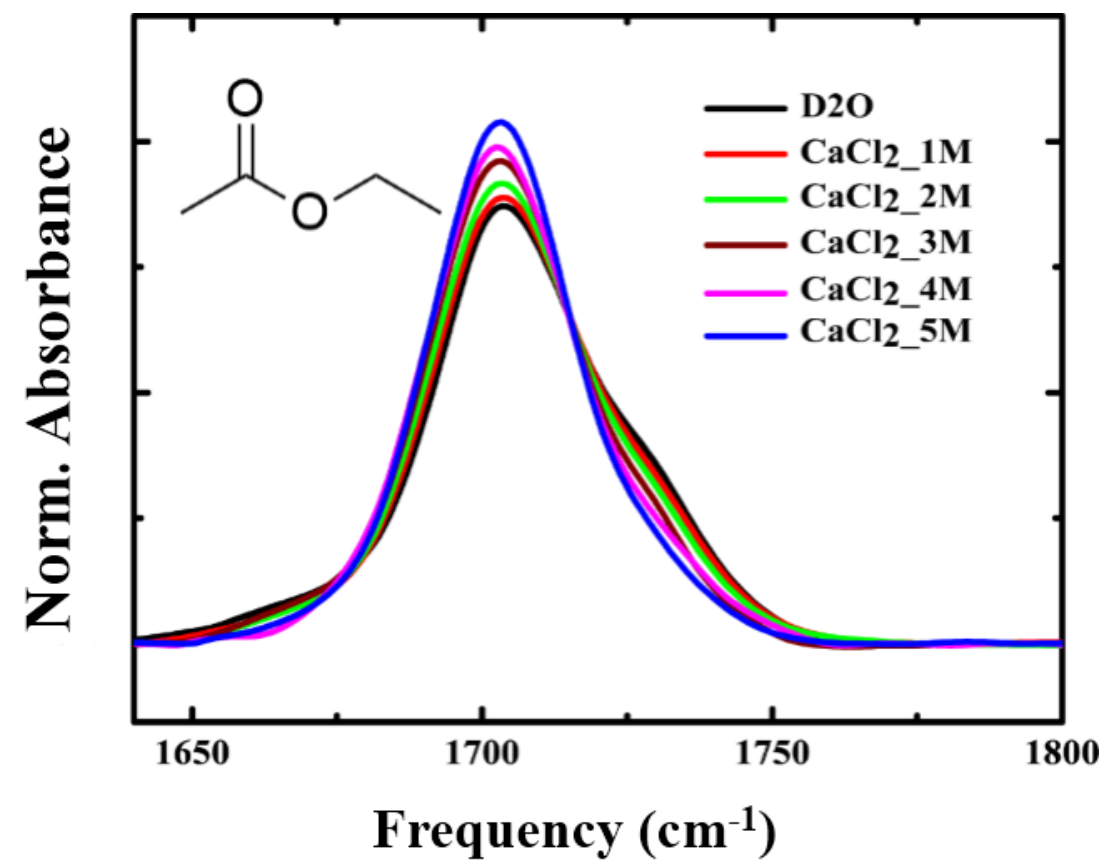

Figure S3. IR spectrum of ethyl acetate (EtOAc) in aqueous solution containing $\mathrm{CaCl}_{2}$ of five different concentrations. The spectrum in neat water $\left(\mathrm{D}_{2} \mathrm{O}\right)$ is also shown as reference. All the spectra have been normalized to the area under the curve. 


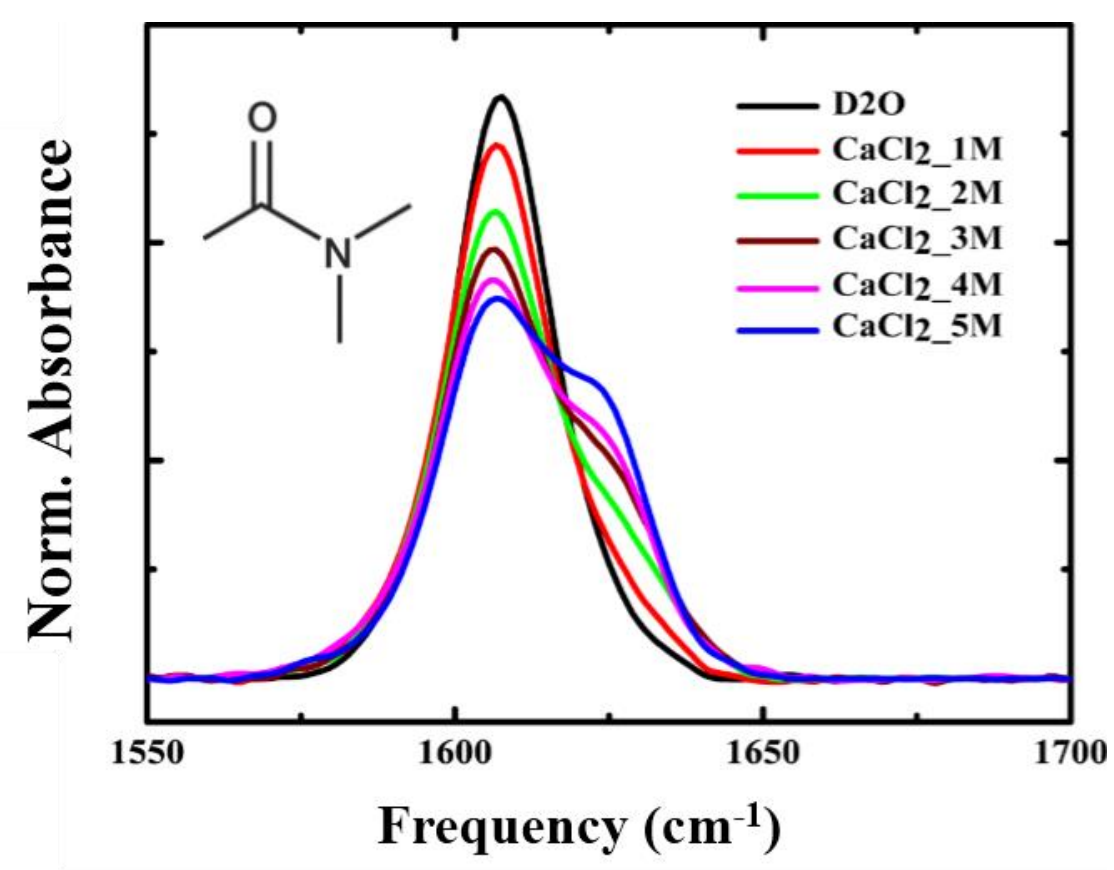

Figure S4. IR spectrum of $\mathrm{N}$, $\mathrm{N}$-dimethylacetamide (DMA) in aqueous solution containing $\mathrm{CaCl}_{2}$ of five different concentrations. The spectrum in neat water $\left(\mathrm{D}_{2} \mathrm{O}\right)$ is also shown as reference. All the spectra have been normalized to the area under the curve.

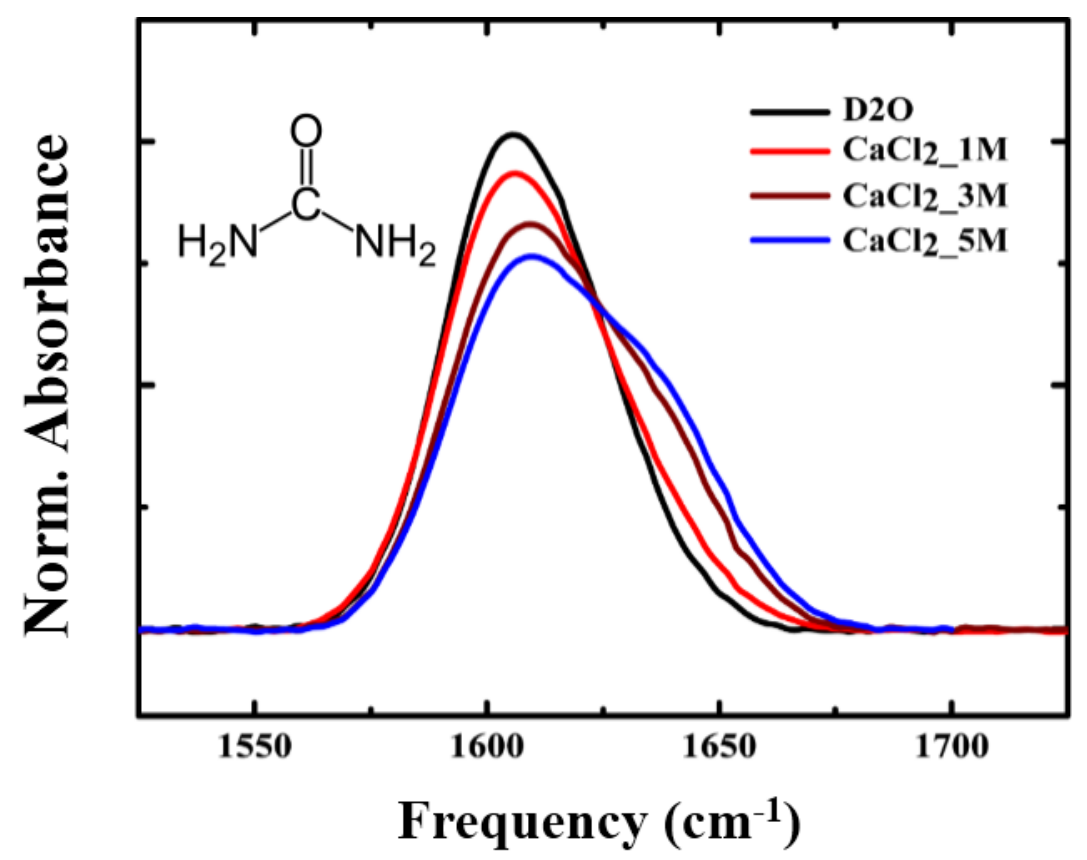

Figure S5. IR spectrum of urea in aqueous solution containing $\mathrm{CaCl}_{2}$ of three different concentrations. The spectrum in neat water $\left(\mathrm{D}_{2} \mathrm{O}\right)$ is also shown as reference. All the spectra have been normalized to the area under the curve. 


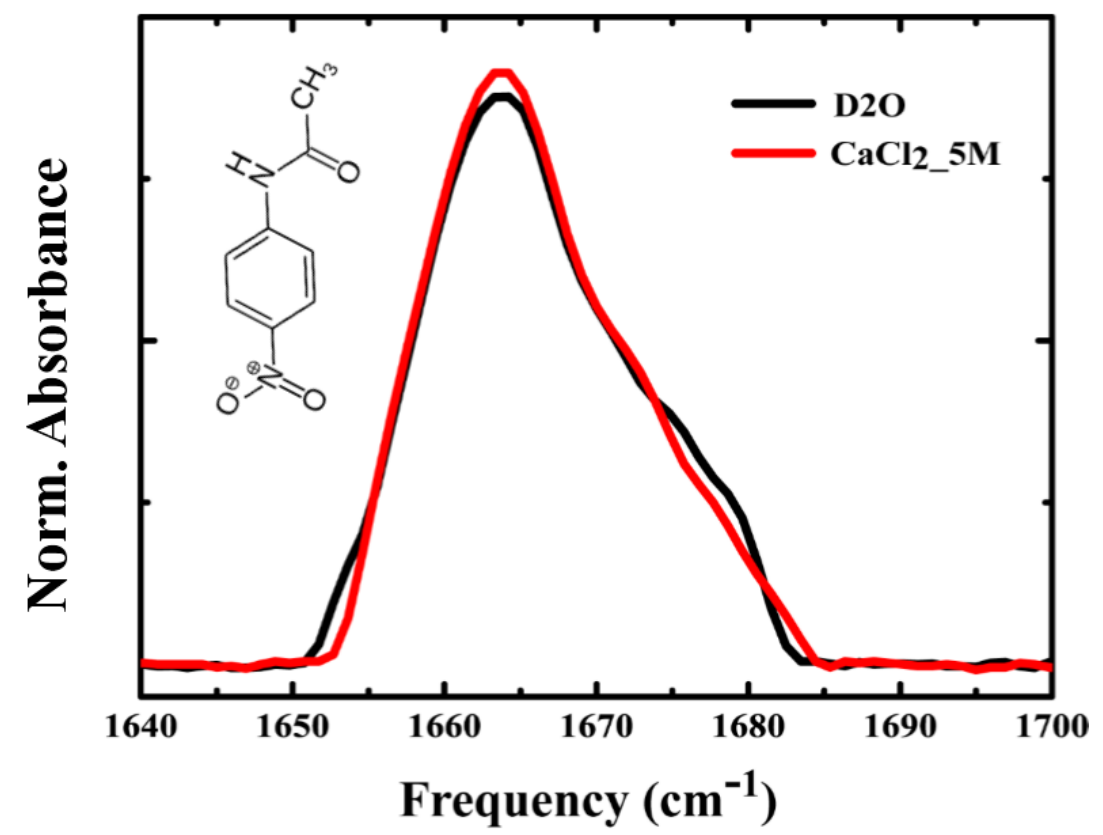

Figure S6. IR spectrum of $p$-nitro acetanilide in aqueous solution containing $5 \mathrm{M} \mathrm{CaCl}_{2}$. The spectrum in neat water $\left(\mathrm{D}_{2} \mathrm{O}\right)$ is also shown as reference. All the spectra have been normalized to the area under the curve.

\section{Section 2. Results from Computations}

(a)

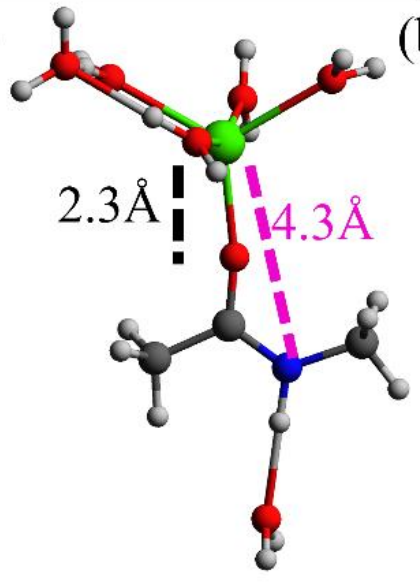

(b)
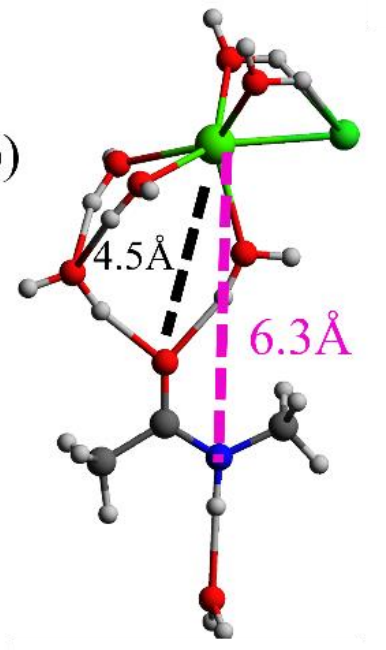

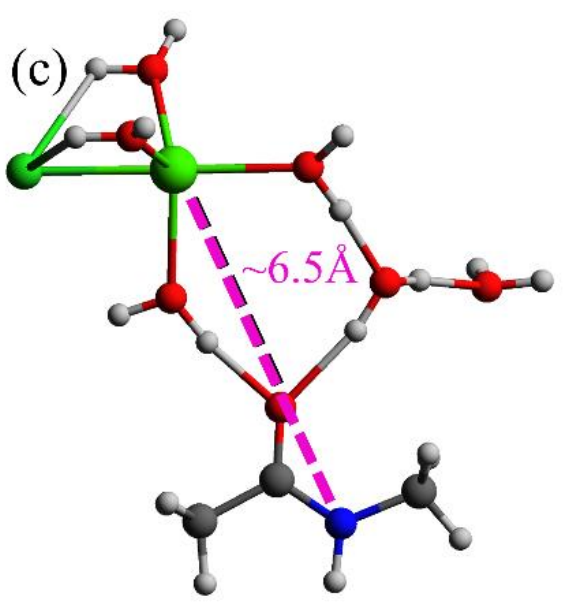

Figure S7. A representative structure of (a) MIN1, (b) MIN2 and (c) MIN3. The distances to $\mathrm{Ca}^{2+}$ is indicated in the figure. 

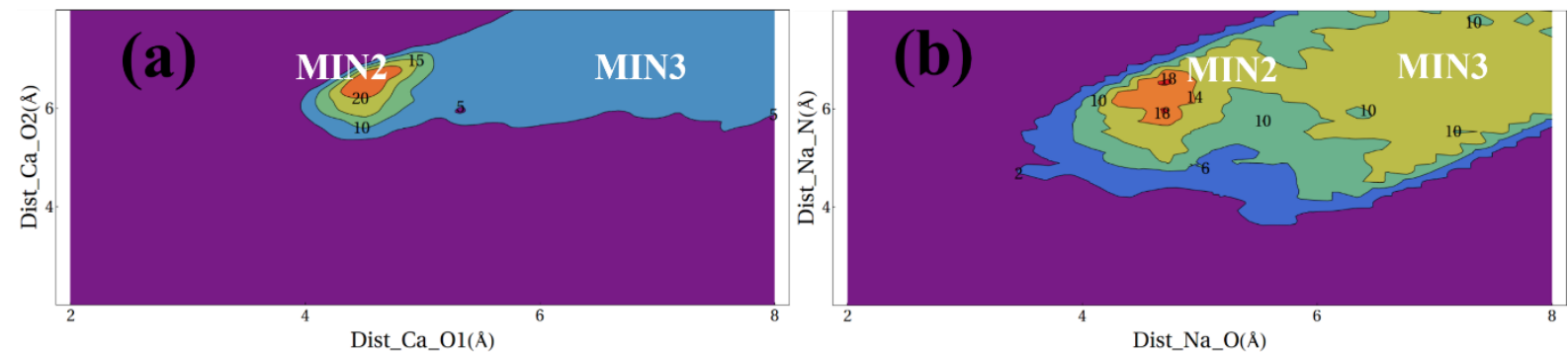

Figure S8. Volume corrected distance distribution of cations around (a) $\mathrm{MeOAc}$ in $5 \mathrm{M} \mathrm{CaCl}_{2}$ and (b) NMA in $5 \mathrm{M} \mathrm{NaCl}$. The distances are measured from the $\mathrm{N}$ and $\mathrm{O}$ atoms for NMA and two oxygen atoms for MeOAc are used. The minima in each distribution are indicated by MIN2 and MIN3.

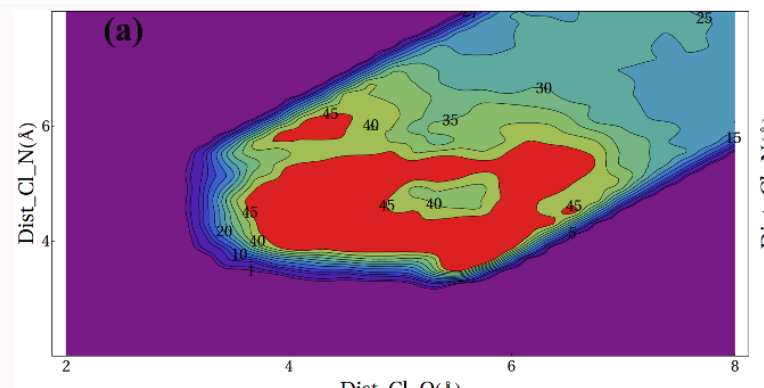

Dist_Cl_O $(\AA)$

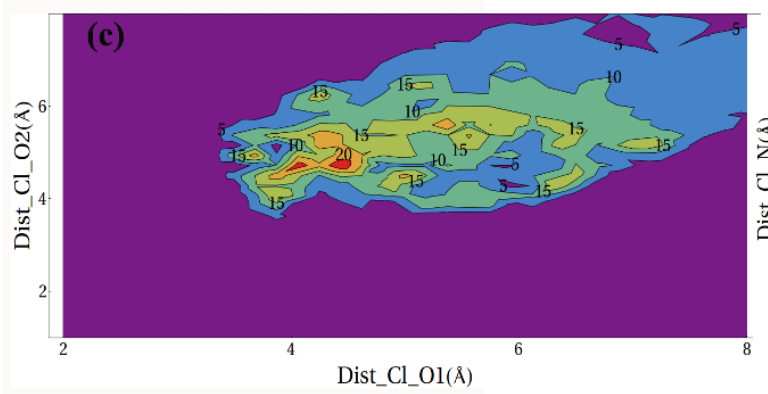

Figure S9. Volume corrected distance distribution of chloride ion around (a) NMA in 5M $\mathrm{CaCl}_{2}$, (b) NMA in $1 \mathrm{M} \mathrm{CaCl}_{2}$, (c) $\mathrm{MeOAc}$ in $5 \mathrm{M} \mathrm{CaCl}_{2}$, and (d) NMA in $5 \mathrm{M} \mathrm{NaCl}$. The distances measured from the $\mathrm{N}$ and $\mathrm{O}$ atoms for NMA and two oxygen atoms for MeOAc are used. This figure shows that $\mathrm{Cl}^{-}$is uniformly distributed around amide oxygen and nitrogen. 
Table S2. IR spectra of carbonyl group $(\mathrm{C}=\mathrm{O})$ and $\mathrm{C}-\mathrm{N} / \mathrm{C}-\mathrm{O}$ group of NMA/MeOAc.

\begin{tabular}{|l|l|l|l|l|l|}
\hline System & Minima & $\begin{array}{l}\mathrm{C}=\mathrm{O} \\
\text { frequency } \\
\left(\mathrm{cm}^{-1}\right)\end{array}$ & $\varepsilon$ & $\begin{array}{l}\text { C-N/C-O } \\
\text { frequency } \\
\left(\mathrm{cm}^{-1}\right)\end{array}$ & $\varepsilon$ \\
\hline $\begin{array}{l}\text { NMA in 5M } \\
\mathrm{CaCl}_{2} \\
\text { solution }\end{array}$ & MIN1 & 1618 & 800 & 1670 & 1900 \\
\cline { 2 - 6 } & MIN2 & 1645 & 1600 & 1630 & 300 \\
\cline { 2 - 6 } & MIN3 & 1665 & 1300 & 1585 & 600 \\
\hline $\begin{array}{l}\mathrm{MeOAc}^{2} \text { in CaCl } \\
\text { solution }\end{array}$ & MIN1* & 1660 & 2300 & 1380 & 500 \\
\cline { 2 - 6 } & MIN2 & 1720 & 1500 & 1320 & 1100 \\
\cline { 2 - 6 } & MIN3 & 1740 & 1600 & 1320 & 1100 \\
\hline
\end{tabular}
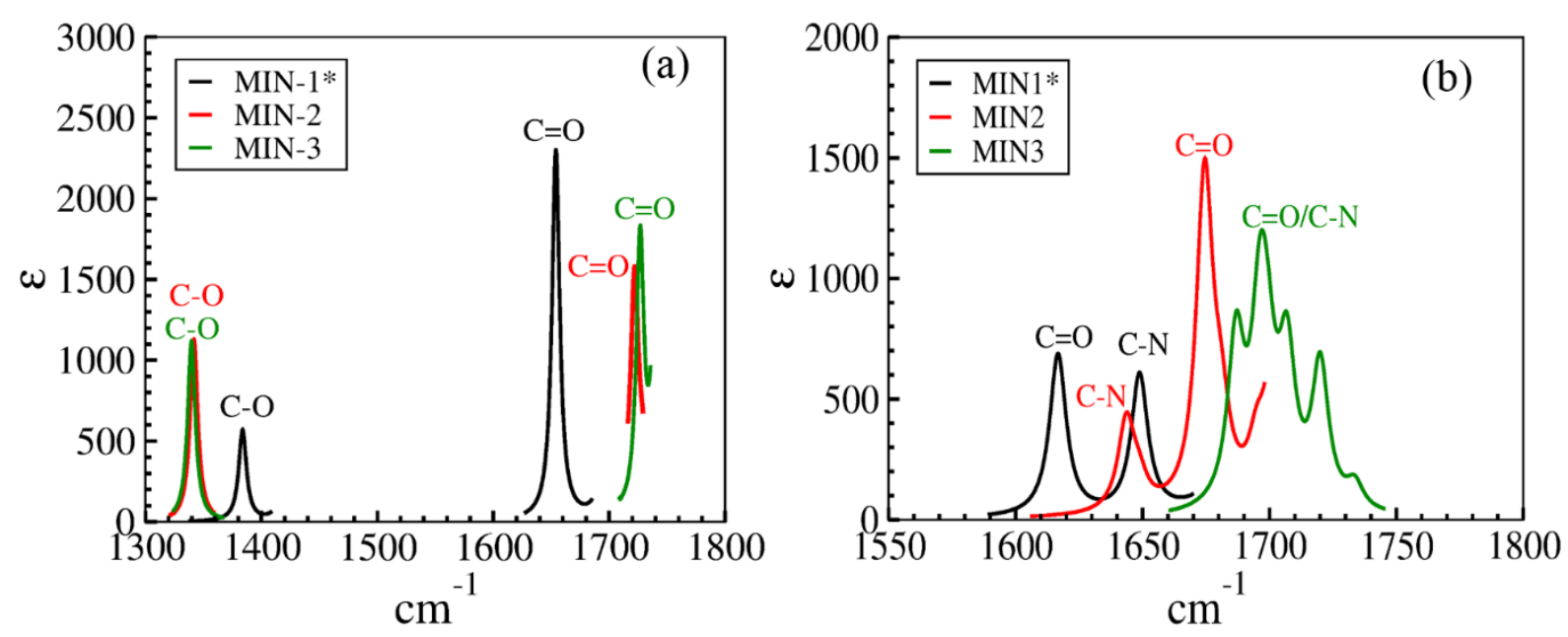

Figure S10. IR spectra of (a) $\mathrm{MeOAc}$ in $\mathrm{CaCl}_{2}$ solution and (b) NMA in $5 \mathrm{M} \mathrm{NaCl}$ solution. Black curves represent the IR spectra when $\mathrm{Ca}^{2+}$ is held very close to $\mathrm{C}=\mathrm{O}(\mathrm{MIN} 1 *)$. Note, we have not observes MIN1* in the simulation. This state was created by using the MIN1 position of $\mathrm{Ca}^{2+}$ from NMA. Red curves represent the IR spectra of the $\mathrm{C}=\mathrm{O}$ and $\mathrm{C}-\mathrm{O} / \mathrm{C}-\mathrm{N}$ at MIN2 structure. Green color represents the IR of the $\mathrm{C}=\mathrm{O}$ and $\mathrm{C}-\mathrm{O} / \mathrm{C}-\mathrm{N}$ at $\mathrm{MIN} 3$ structure. 

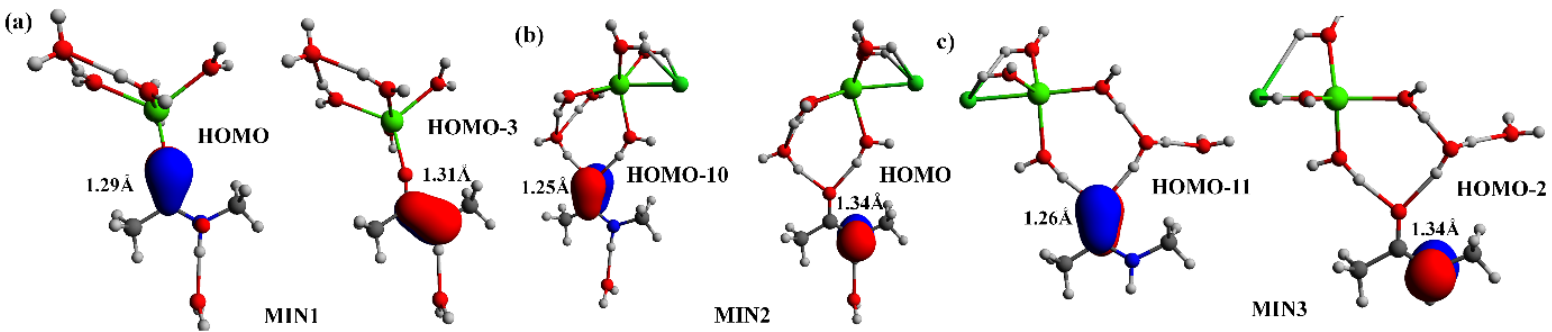

Figure S11. The MO of NMA for different states. (a) MIN1 (b) MIN2 and (c) MIN3. The C=O MO is first HOMO in the MIN1, whereas in the MIN2 and MIN3 it is HOMO-10 and HOMO-11, respectively. Thus binding of $\mathrm{Ca}^{2+}$ decreases the strength of $\mathrm{C}=\mathrm{O}$ bond. Moreover, the lone pair of $\mathrm{N}$ is delocalized to the $\mathrm{C}$ of $\mathrm{C}=\mathrm{O}$ in MIN1 whereas, in MIN2 and MIN3 the electron is localized at $\mathrm{N}$ alone. Therefore, in MIN1, C-N bond adopts the partial double bonded character.

Table S3. Bond order and bond length of carbonyl group $(\mathrm{C}=\mathrm{O})$ and $\mathrm{C}-\mathrm{N}$ group of NMA/MeOAc.

\begin{tabular}{|l|l|l|l|}
\hline System & Minima & $\begin{array}{l}\text { Bond } \\
\text { Order } \\
(\mathrm{C}=\mathrm{O})\end{array}$ & $\begin{array}{l}\text { Bond } \\
\text { Order } \\
(\mathrm{C}-\mathrm{N} / \mathrm{O})\end{array}$ \\
\hline $\begin{array}{l}\text { NMA in } 5 \mathrm{M} \\
\begin{array}{l}\mathrm{CaCl} \\
\text { solution }\end{array}\end{array}$ & MIN1 & $1(1.29 \AA)$ & $2(1.31 \AA)$ \\
\cline { 2 - 4 } & MIN2 & $2(1.25 \AA)$ & $1(1.34 \AA)$ \\
\cline { 2 - 4 } & MIN3 & $2(1.26 \AA)$ & $1(1.34 \AA)$ \\
\hline $\begin{array}{l}\text { MeOAc in } \\
5 \mathrm{M} \mathrm{CaCl} \\
\text { solution }\end{array}$ & MIN1* & $2(1.26 \AA)$ & $1(1.33 \AA)$ \\
\cline { 2 - 4 } & MIN2 & $2(1.25 \AA)$ & $1(1.33 \AA)$ \\
\cline { 2 - 4 } & MIN3 & $2(1.25 \AA)$ & $1(1.33 \AA)$ \\
\hline
\end{tabular}

Table S4. IR spectra of $\mathrm{CO}$ and $\mathrm{CN}$ with different number of water molecules used around the $\mathrm{N}$. The number of water molecules are mentioned in the parenthesis.

\begin{tabular}{|l|l|l|l|l|l|}
\hline System & Minima & \multicolumn{2}{l|}{ C=O frequency $\left(\mathrm{cm}^{-1}\right)$} & \multicolumn{2}{l|}{ C-N/C-O frequency $\left(\mathrm{cm}^{-1}\right)$} \\
\hline \multirow{3}{*}{$\begin{array}{l}\text { NMA in 5M } \\
\mathrm{CaCl}_{2} \text { solution }\end{array}$} & & Less Water & More Water & Less Water & More Water \\
\cline { 2 - 6 } & MIN1 & $1618(6)$ & $1620(20)$ & $1670(6)$ & $1668(20)$ \\
\cline { 2 - 6 } & MIN2 & $1645(7)$ & $1639(22)$ & $1630(7)$ & $1648(22)$ \\
\cline { 2 - 6 } & MIN3 & $1665(5)$ & $1660(38)$ & $1585(5)$ & $1580(38)$ \\
\hline
\end{tabular}




\section{Section 3. 2D IR spectra}


Figure S12. 2DIR spectra of an aqueous solution of $\mathrm{N}$-methylacetamide in the presence of $5 \mathrm{M} \mathrm{CaCl}_{2}$ at (a) 0 , (b) 5 ps, (c) 10 ps and (d) 15 ps waiting times. 


\section{Section 4. NMA Aggregation}

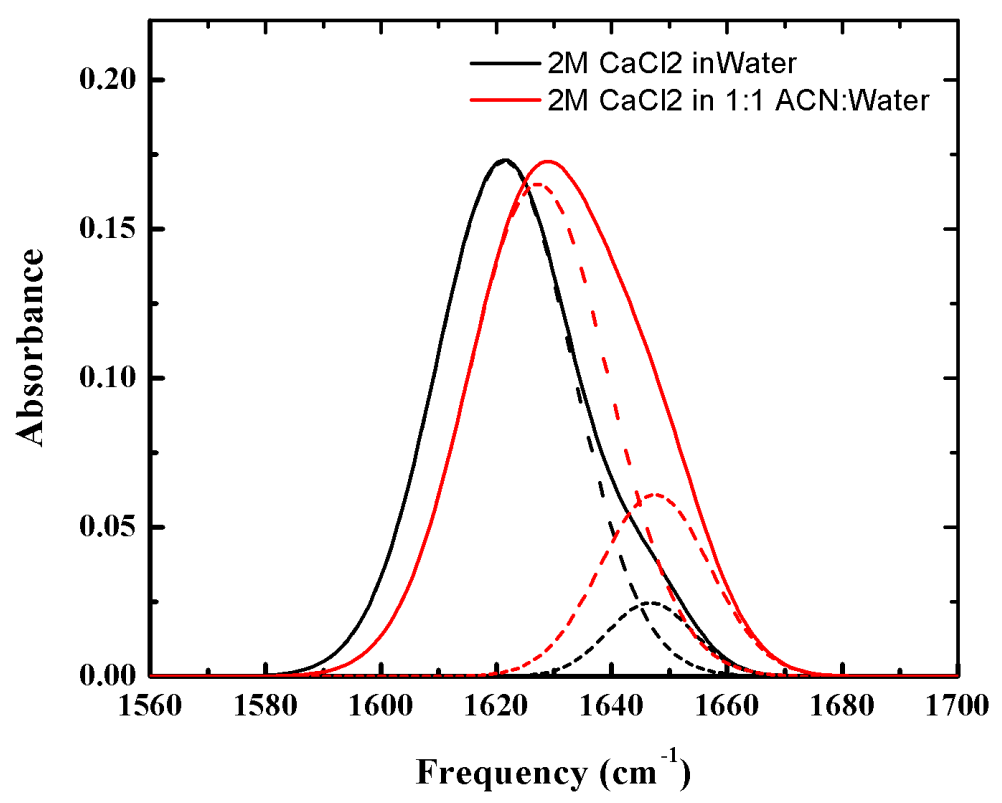

Figure S13. IR spectrum of NMA in $2 \mathrm{M} \mathrm{CaCl}_{2}$ solution in neat water and $1: 1(\mathrm{v}: \mathrm{v})$ acetonitrile/water mixture.
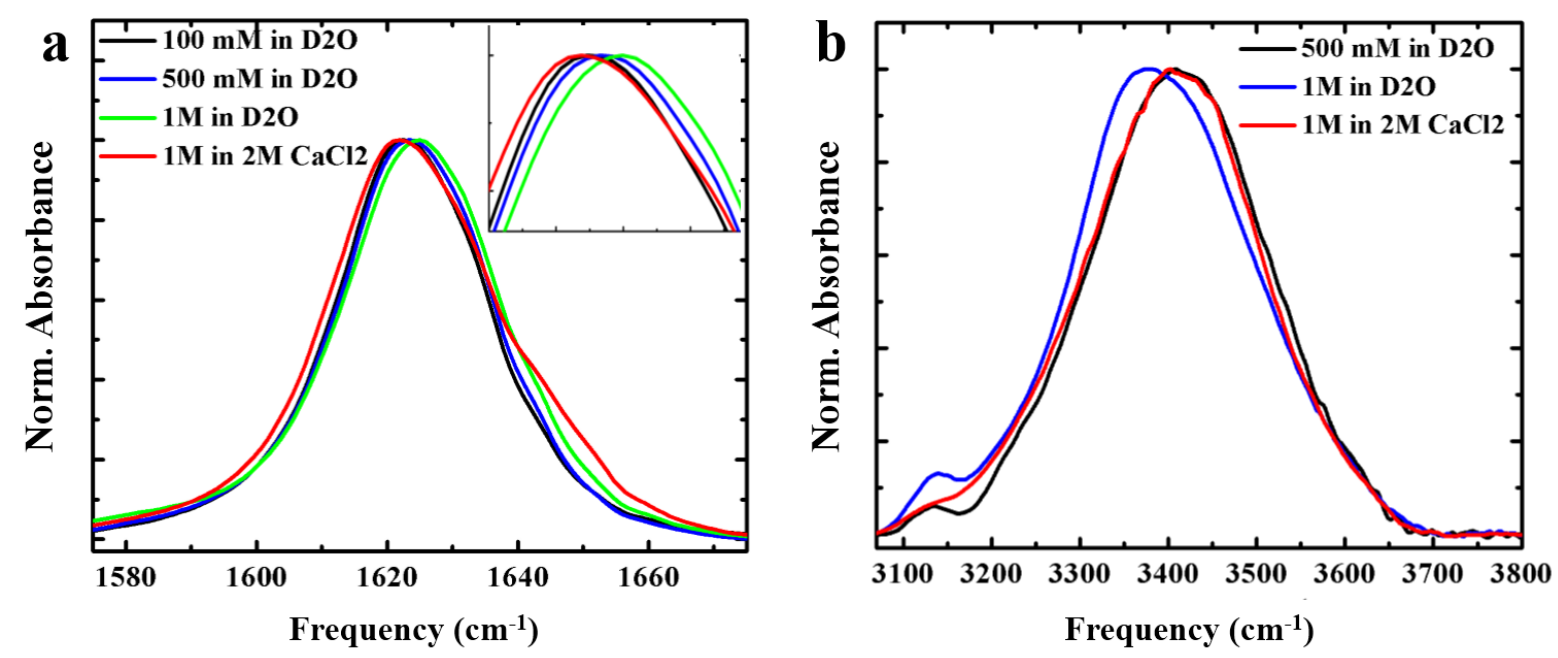

Figure S14. Normalised IR spectrum of NMA a) amide-I b) N-H stretch in $\mathrm{D}_{2} \mathrm{O}$ with different amide concentrations and in $2 \mathrm{M} \mathrm{CaCl}_{2}$ with high amide concentration $(1 \mathrm{M})$.

It has been recently reported that NMA aggregates show a spectral shift in the amide-I band due to a convolution of hydrogen bonding $(\mathrm{NH} \ldots \mathrm{C}=\mathrm{O})$ and exitonic coupling. Increasing concentration of NMA (from $100 \mathrm{mM}$ to $1 \mathrm{M}$ ) in neat water $\left(\mathrm{D}_{2} \mathrm{O}\right)$ indeed shows an increasing spectra shift. With increasing amide concentration in neat water, the amide I peak blue shifts while N-H stretching shows red shift. This shift in the peak position is observed due to the aggregation of amide through $\mathrm{C}=\mathrm{O} \ldots \mathrm{NH}$ hydrogen bonded complexes, thereby replacing 
$\mathrm{C}=\mathrm{O}$... water and $\mathrm{NH} . .$. water hydrogen bonds. The respective shifts in the $\mathrm{C}=\mathrm{O}$ and $\mathrm{NH}$ stretches upon aggregation can be explained by the relative strengths of the hydrogen bonds. ${ }^{1}$ The $\mathrm{C}=\mathrm{O} \ldots \mathrm{H}-\mathrm{N}$ hydrogen bond is weaker than the $\mathrm{C}=\mathrm{O} \ldots$ water hydrogen bond, but stronger than the water...H-N hydrogen bond. However upon addition of $2 \mathrm{M} \mathrm{CaCl}_{2}$, the spectral shifts in both the amide-I and $\mathrm{NH}$ peaks are reversed, indicating that the $\mathrm{CaCl}_{2}$ can restrict the aggregation process.

References

1. Dixon, D. A.; Dobbs, K. D.; Valentini, J. J., Amide-Water and Amide-Amide Hydrogen Bond Strengths. J. Phys. Chem. 1994, 98, 13435-13439. 